\title{
Use of Sildenafil in Patients with Cardiovascular Disease
}

\author{
A rmênio Costa Guimarães, Marcus Vinícius Bolívar Malachias, O távio Rizzi Coelho, \\ Emílio Cesar Zilli, Rafael Leite Luna
}

\section{Introduction}

Erectile dysfunction, formerly called impotence, is the inability of the male to achieve or maintain penile erection and thus engage in coitus ${ }^{1}$. It is common among patients with cardiovascular diseases or their risk factors. This dysfunction occurs mainly among individuals with coronary artery disease, after episodes of acute ischemic syndrome, hypertensive patients underpharmacologic treatment, and among patients with heart failure. In approximately $85 \%$ of these cases, the fear of a cardiac event during coitus constitutes an important factor for erectile dysfunction ${ }^{2-4}$.

Discovery of sildenafil citrate has represented a great development in the treatment of erectile dysfunction; it may benefit, among many others, those patients with cardiovascular diseases or with their risk factors ${ }^{5}$. Even though clinical trials including more than 3,700 patients with erectile dysfunction, 2,000 of them in controlled studies with placebo, have shown a good tolerance for the medication, more intense circulatory side effects may occur in individuals with cardiovascular disease, mainly those patients using medications with organic nitrates ${ }^{6}$. These circumstances require recommendations by specialists so that sildenafil can be safely used.

\section{Epidemiology}

In the Massachusetts Male Aging Study (MMAS), erectile dysfunction significantly correlated with 3 groups of diseases: atherosclerosis, hypertension, and diabetes mellitus ${ }^{7}$. The most important organic factor involved in this dysfunction is impairment of penile blood flow, common in men above 50 years of age with atherosclerosis or diabetes. It is estimated that $50 \%$ (ranging from $28 \%$ to $59 \%$ ) of diabetic patients have erectile dysfunction.

\section{Sildenafil}

Mechanism of action - Sildenafil belongs to the class

Força-Tarefa para o Uso do Sildenafil e Doenças Cardiovasculares (Task Force for the Use of Sildenafil and Cardiovascular Diseases)

Mailing address: Armênio Costa Guimarães - Av. Garibaldi, 1555 - 40210-070 Salvador, BA - Brazil of phosphodiesterase inhibitors. The erectile action of sildenafil combines increase in arterial flow with reduction in the venous flow of cavernous body of penis. Sildenafil leads to relaxation of smooth muscle of penile arteries and trabeculae surrounding the sinusoidal spaces, resulting in a greater engorgement of cavernous body. The trabeculae of engorged sinusoidal spaces compress the penile venules against the tunica albuginea, reducing venous flow, contributing to maintenance of engorgement of cavernous body ${ }^{8}$. Relaxation of this smooth muscle results from a decrease in intracellular calcium mediated by accumulation of the second messenger, the cyclic guanosine monophosphate (cGMP), whose production results from activation of guanyl cyclase by nitric oxide produced by the stimulus of endothelial cells generated by sexual desire. The limiting factor in this process is degradation of cGMP by the enzyme 5 phosphodiesterase (PDE5) present in high concentrations in the penile structures. Sildenafil facilitates erection due to its high specificity and potency as an inhibitor of this phosphodiesterase ${ }^{9,10}$. Acting in the final phase of the biochemical cycle of erection, the action of sildenafil depends on sexual desire and, therefore, it is not an aphrodisiac.

Lower concentrations of PDE5 may also be found in the smooth muscle of arteries in general, of viscera and trachea, and in platelets. Seven types of phosphodiesterases have already been identified. Sildenafil has a lower inhibiting power upon other isoenzymes of phosphodiesterase as compared with PDE5. It has a weak selectivity (1,000 times smaller) for PDE2 (predominates in the adrenal cortex), PDE3 (smooth muscle, platelets and myocardium), and PDE4 (lymphocytes of the brain and lungs). It has a moderate selectivity ( 80 or more times smaller) for PDE1 (predominates in the brain, kidneys and smooth muscle) and an only 10-times smaller selectivity for PDE6 (photoreceptors of the retina), the probable cause of visual disorders that may occur with the use of sildenafil. The 4,000-times lower selectivity for PDE3 (involved in myocardial contractility) is important because the inhibitors of this isoenzyme (milrinone, vesnarinone, and enoximone) used for treating heart failure cause cardiac arrhythmia and have other noxious effects ${ }^{8,10}$.

\section{Pharmacokinetics and metabolism}

The peak of plasma concentration of sildenafil occurs 
30 to 120 minutes (mean of 60 minutes) after oral ingestion, during fasting. In the liver, sildenafil is partially converted into a metabolite that accounts for approximately $20 \%$ of its pharmacological action, and both circulate almost completely bound to plasma proteins $(96 \%)$. Each one has a halflife of 4 hours. The major hepatic metabolic pathways are the cytochrome P4503A4 (main) and P4502C9 (secondary) ${ }^{8,11}$. Excretion is predominantly fecal $(80 \%)$; only $13 \%$ are urinary. For a given oral dose of sildenafil, plasma concentrations of the drug may be $40 \%$ higher in individuals above 65 years of age, $80 \%$ higher in individuals with hepatic failure, and $100 \%$ higher in individuals with severe renal failure (creatinine clearance $<30 \mathrm{~mL} / \mathrm{min}$ ). Plasma concentrations of sildenafil may also increase with the concomitant use of potent inhibitors of the cytochrome P450 3A4, such as erythromycin, clarithromycin, cimetidine, and antifungal agents, such as ketoconazole and itraconazole. Protease inhibitors used in the treatment of AIDS, such as indinavir, ritonavir, nelfinavir, and saquinavir, which are potent inhibitors of cytochrome P450 3A4, even though not formally tested, may interfere in the same way with the metabolism of sildenafil ${ }^{11}$ (table I).

\section{Pharmacodynamics}

Effect on penile tumescence-Sildenafil is effective in erectile dysfunction of various causes, such as vascular (diabetes), neuroreflexogenic (spinal cord damage), and psychogenic, which has been confirmed in 21 multicenter double-blind randomized trials controlled with placebo ${ }^{11,12}$.

Cardiovascular effects - 1) Sildenafil does not interfere with myocardial contractility in healthy volunteers. However, studies in patients with heart failure are still lacking; 2) Sildenafil causes a mild and transient drop in systolic ( 8 to $10 \mathrm{mmHg}$ ) and diastolic ( 4 to $6 \mathrm{mmHg}$ ) blood pressures, with a peak one hour after the oral dose, ingested during fasting, returning to the baseline in 4 hours. This effect results from the peripheral arterial and venous vasodilating action of sildenafil, and it is not dose- (25 to 100 $\mathrm{mg}$ ) or age-dependent, and seldom causes orthostatic hypotension; 3) sildenafil does not have a significant effect on heart rate ${ }^{11,12}$.

Effect on platelets - Bleeding episodes and increase in the bleeding and prothrombin times have not been observed, even in patients using acetylsalicylic acid or warfarin. However, assessment with the simultaneous use of other platelet antiaggregating agents (ticlopidine, clopidogrel, and dipyridamole) does not exist, nor assessment in patients with blood disorders; therefore, caution is advisable in such situations ${ }^{11,12}$.

Effect on vision - Increase in light sensitivity and a blue-greenish or blurred vision due to the inhibiting action of sildenafil on 6 phosphodiesterase present in the retinal photoreceptors may occur. Patients, in whom these visual disorders may impair their activities, such as operators of automotive vehicles and airplanes, should be informed. Sildenafil should be carefully used in the presence of retinitis pigmentosa ${ }^{11,12}$.

Adverse effects - 1) Vasodilating effects: headache (16\%), flushing (10\%), and rhinitis (4\%). Dizziness (2\%), hypotension and postural hypotension ( $2 \%$ each) occurred with equal frequency in the sildenafil and placebo groups; 2 ) Gastrointestinal effects: dyspepsia due to reflux $(7 \%) ; 3$ ) Visual effects: increase in light sensitivity or blue-greenish or blurred vision (3\%), mainly with doses of $100 \mathrm{mg}$; 4) Musculoskeletal effects: muscle pains, especially with multiple doses, without alterations in the concentration of creatinine phosphokinase and in the electromyogram; 5) Priapism: occasionally reported ${ }^{11,12}$.

\begin{tabular}{|c|c|c|c|c|}
\hline \multicolumn{5}{|c|}{ Table I - Chemicals metabolized by or inhibiting cytochrome P450 3A4 } \\
\hline $\begin{array}{l}\text { Antibiotics/antifungal } \\
\text { agents }\end{array}$ & Cardiovascular action & $\begin{array}{l}\text { Lipid-lowering drugs } \\
\text { (statins) }\end{array}$ & Central nervous system & Others \\
\hline $\begin{array}{l}\text { Clarithromycin } \\
\text { Clotrimazole } \\
\text { Erythromycin } \\
\text { Fluconazole } \\
\text { Itraconazole } \\
\text { Ketoconazole } \\
\text { Miconazole } \\
\text { Norfloxacin }\end{array}$ & $\begin{array}{l}\text { Amiodarone } \\
\text { Amlodipine } \\
\text { Digitoxin } \\
\text { Diltiazem } \\
\text { Disopyramide } \\
\text { Felodipine } \\
\text { Isradipine } \\
\text { Losartan } \\
\text { Nifedipine } \\
\text { Quinidine } \\
\text { Verapamil }\end{array}$ & $\begin{array}{l}\text { Atorvastatin } \\
\text { Cerivastatin } \\
\text { Lovastatin } \\
\text { Simvastatin }\end{array}$ & $\begin{array}{l}\text { Alprazolam } \\
\text { Carbamazepine } \\
\text { Fluoxetine } \\
\text { Imipramine } \\
\text { Nefazodone } \\
\text { Phenobarbital } \\
\text { Phenytoin } \\
\text { Sertraline } \\
\text { Triazolam }\end{array}$ & $\begin{array}{l}\text { Acetaminophen } \\
\text { Astemizole } \\
\text { Cimetidine } \\
\text { Cisapride } \\
\text { Cyclosporine } \\
\text { Dexamethasone } \\
\text { Ethinylestrenol } \\
\text { Rifampicin } \\
\text { Terfenadine } \\
\text { Theophylline } \\
\text { Troglitazone } \\
\text { Sildenafil } \\
\text { Protease inhibitors: } \\
\text { Indinavir } \\
\text { Ritonavir } \\
\text { Nelfinavir } \\
\text { Saquinavir } \\
\text { "Grapefruit" }\end{array}$ \\
\hline
\end{tabular}




\section{Drug-Drug interactions}

Nitrates-Sildenafil increases the vasodilating action of nitrates and may cause potentially fatal severe hypotension. Based on the pharmacokinetic profile of sildenafil, nitrates should not be used within the 24 hours following the use of sildenafil. This period should be expanded in those situations prolonging the action of sildenafil (see pharmacokinetics and metabolism). On the other hand, the use of sildenafil is contraindicated if the nitrate was used in the preceding 24 hours, even sublingual nitrate. In the case of oral route, this precaution is justified because the potential effect of residual traces of nitrate in the organism has not yet been well clarified. In the case of the sublingual witrate, duration of the action is short, but its use may suggest the need for repeating the dose during or after the intercourse facilitated by sildenafil. Table II shows the medications based on organic nitrates available in the Brazilian market. The anesthetic agent nitrous oxide does not interact with sildenafil ${ }^{11}$.

Antihypertensive medications-Adverse hypotensive effects have not been observed with the antagonists of the calcium channels, angiotensin-converting enzyme inhibitors, thiazides, loop diuretics, potassium sparing diuretics, and alpha- and beta-blockers. In a specific study with amlodipine, the response to sildenafil was not different from the response to placebo. However, one should be cautious when the therapeutical scheme comprises a drug that uses or inhibits the cytochrome P4503A4 (table I) ${ }^{6,11}$.

Other medications - Sildenafil does not interact with aspirin and warfarin, and no data regarding antiaggregating agents such as ticlopidine, clopidogrel and dipyridamole are available. In regard to cimetidine and erythromycin, both inhibitors of the cytochrome P4503A4, it is advisable to begin with low doses of sildenafil $(25 \mathrm{mg})$. Other medications are also metabolized through thisroute; therefore, a competitive inhibition may occur, but the effects of their interaction with sildenafil have not yet been adequately tested ${ }^{11}$ (table I).

Other associated conditions -1$)$ renal failure: mild ( 80 to $50 \mathrm{~mL} / \mathrm{min}$ ) and moderate ( 49 to $30 \mathrm{~mL} / \mathrm{min}$ ) reductions in the creatinine clearance do not significantly affect the metabolism of sildenafil. In cases of severe renal failure (creatinine clearance $<30 \mathrm{~mL} / \mathrm{min}$ ), duplication of the plasma concentration of sildenafil occurs, intensifying and prolonging its effects. In such cases, an initial dose of $25 \mathrm{mg}$ is advisable.
More caution is recommended in cases of concomitant administration of a drug that reduces blood pressure ${ }^{11}$; 2) elderly patients: similar caution should be observed with elderly patients, in whom the plasma concentration of creatinine in the presence of reduction in the muscle mass overestimates the value of creatinine clearance; 3 ) hepatic failure: the same caution with renal failure should be observed in this situation.

\section{Sildenafil in the patient with cardiovascular disease}

Circulatory effects in sexual intercourse - a) in healthy individuals: cardiac overload and metabolic consumption are variable. In the laboratory, healthy men with their usual female partners reach a heart rate of approximately $110 \mathrm{bpm}$ with female-on-top-coitus and of approximately $127 \mathrm{bpm}$ with male-on-top coitus, corresponding to an exercise of 2.5 to $3.3 \mathrm{METs}^{11}$; $\mathbf{b}$ ) in patients with coronary arterial disease: in NYHA functional classes I and II patients without antianginal medication, ischemia occurred during sexual intercourse in $1 / 3$ of the patients, and it was silent $2 / 3$ of the time. All these patients had ischemia on treadmill stress testing. The mean heart rate varied around $118 \mathrm{bpm}$, but in some patients it reached $185 \mathrm{bpm}$ at orgasm. In a study with 19 patients, angina during sexual intercourse did not occur with the use of beta-blockers, in parallel with reduction in the mean maximum heart rate from $125 \mathrm{bpm}$ to $82 \mathrm{bpm}$. Other small studies showed that coitus may cause ventricular extrasystoles not triggered by other stimuli $\left.{ }^{12} ; \mathbf{c}\right)$ death of patients with coronary artery disease during sexual intercourse: death during sexual intercourse is rare $(0.6 \%$ of the cases of sudden death). Even though coitus may trigger an acute myocardial infarction, the relative risk in the 2 hours following sexual activity is low (2.5, CI95\%, 1.7 to 3.7). And even in this case, direct contribution of coitus to acute myocardial infarction seems to have occurred only $0.9 \%$ of the time. Regular physical exercise seems to reduce the risk of acute myocardial infarction during coitus ${ }^{12}$. It is important to emphasize that these encouraging data do not apply to patients, who, using or not using sildenafil, increase their circulatory and metabolic overload beyond their usual limits, as may happen in extramarital coitus or in coitus after excessive ingestion of food and alcoholic beverages; d) risk assessment: the treadmill stress test may assess the potential risk of a normal coitus in a patient with coronary artery disease. The risk of developing myocardial ischemia during coitus is low if a load of 5 to 6 METs can be reached without triggering ischemia or arrhythmia induced by exercise ${ }^{11}$.

\begin{tabular}{|lll|}
\hline & Table II - Medications containing organic nitrates marketed in Brazil \\
\hline Isosorbide dinitrate & Isosorbide mononitrate & Nitroglycerin \\
\hline Isocord (Asta Médica) & Monocordil (Baldacci) & Nitradisc (Searle) \\
Isordil (Wyeth) & Cincordil (Wyeth) & Nitroderm TTS (Novartis) \\
Isossorbida (Cazi) & & Tridil (Cristália) \\
Isossorbida (Sanval) & & \\
\hline
\end{tabular}




\section{Effects of sildenafil in patients with coronary artery disease}

In double-blind controlled randomized studies, $70 \%$ of the ischemic patients using sildenafil reported improvement in erectile dysfunction versus $20 \%$ in the placebo group. The medication was well tolerated, with the incidence of collateral cardiovascular effects in $5 \%$ of the patients in the sildenafil group and in $3 \%$ of the patients in the placebo group. More severe problems, such as acute myocardial infarction and unstable angina, occurred in 3\% and $2 \%$ of the patients in the sildenafil and placebo groups, respectively. On the other hand, in patients without coronary artery disease, the incidence of these more severe events was lower than $1 \%$ for both the sildenafil and placebo groups ${ }^{12}$.

\section{Death and sildenafil}

Between April and November 1998, the United States Food and Drug Administration (FDA) confirmed that 130 patients died after taking sildenafil. Of these patients, 80 $(61.5 \%)$ had a cardiovascular event (acute myocardial infarction in 41, cardiac arrest in 27, stroke in 3, cardiac symptoms in 6 , and coronary artery disease in 3 others); 2 patients died due to homicide or drowning, and 48 died due to unknown causes. In 106 patients with a known age, the mean age was 64 years (29 to 87 years). Sildenafil dosage varied from 25 to $100 \mathrm{mg}$ and one patient had an overdose. Sixteen patients took nitrate and one used medication with a nitrate base, but its use was not confirmed. Forty (34\%) patients died in the first 4 to 5 hours after using sildenafil; 27 of them died during or right after the coitus. In the remaining, the periods of time in relation to coitus were increasingly high: 6 patients died after 6 hours, 8 patients died on the day after, 5 died 2 days after the coitus, and 4 patients died 3 to 4 days after the coitus. In 61 patients these periods were not known. Considering this temporal relation with the use of sildenafil, this mortality is markedly lower than that expected for the American male population with a similar mean age. Therefore, considering that the deaths occurred in a period of 8 months, coinciding with 6.4 million prescriptions of sildenafil, 4 deaths occurred per week. This mortality is markedly lower than the total cardiovascular mortality expected, which is 150 deaths per week per each million men ${ }^{12}$.

\section{Recommendations for the use of sildenafil in patients with cardiovascular disease}

1) Sildenafil is contraindicated in patients using longand short-acting nitrates due to the possibility of developing potentially fatal severe hypotension.

2) In patients with stable coronary artery disease treated with long-acting nitrates, one may consider the possibility of suspending the nitrate in accordance with the patient, so that sildenafil can be used.

3) Patients not using long-acting nitrates but requiring nitrates sublingual for treatment of episodes of angina should be informed about the hazarg of using sildenafil, unless the nitrate can be replaced by an alternative medication with no risk of interaction with sildenafil.

4) Any use of nitrate is contraindicated in the 24 hours following the use of sildenafil. Sildenafil is also contraindicated if any nitrate has been used in the preceding 24 hours.

5) High-risk cardiovascular patients, including patients with atherosclerotic disease, NYHA functional classes II and III patients individuals above 65 years of age, hypertensive and, diabetic patients, smokers, patients with moderate to severe dyslipidemia, and obese individuals, even if not having asked for sildenafil, should be informed about the potential severe risk of sildenafil-nitrate interaction. This should be done because patients may obtain sildenafil by other means without the recommendations necessary for its use.

6) High-risk cardiovascular patients should be previously assessed through a treadmill stress test. The risk of ischemia during coitus is low if they do not develop clinical or electrocardiographic signs, of ischemia and or arrhythmia, until a load of 5 to 6 METs is reached. These load limits are valid for coitus with the usual partner, in a familiar environment, and without additional overload of excessive consumption of food and alcoholic beverages. Patients without sexual activity for a long period should be advised to moderate their physical activity and anxiety during their return to sexual activity.

7) In patients without ischemia and or arrhythmia, or both, on the treadmill stress test with load lower than 5 to 6 METs, the use of sildenafil should be conditioned to the clinical situation of the patient.

8) It is convenient that patients using vasodilators and diuretics simultaneously should be monitored for a hypotensive response to sildenafil.

9) Physicians and allied health personal emergency departments should be instructed to routinely ask patients about the use of sildenafil.

10) Patients using sildenafil should be instructed to tell about the use of sildenafil in case of an emergency.

11) An initial dose of $25 \mathrm{mg}$ should be recommended in all situations that may increase the plasma concentration of sildenafil or potentiate its vasodilating effect and that do not constitute a formal contraindication for its use.

\section{Treatment of acute ischemic syndromes in patients using sildenafil}

Initial treatment of the precordial pain suspicious of angina - Carefully identify when the last dose of sildenafil 
was taken. Do not use any type of nitrate if sildenafil has been taken within the preceding 24 hours. From 24 to 48 hours after use of sildenafil, nitrate may be administered if no associated conditions increasing plasma concentration or delaying metabolism of sildenafil, such as age above 65 years, severe renal or hepatic failure, or simultaneous use of inhibitors of cytochrome P450 3A4, exist. In such instances, nitrates should only be used if conditions for the treatment of a possible severe hypotensive crisis exist. For the treatment of precordial pain no data about drug interactions are available contraindicating the use of sildenafil with aspirin, betablockers, calcium channel antagonists, or narcotics.

Patients with acute myocardial infarction-The same previous precautions should be taken. So far, no restraints regarding the use of heparin, cumarin, and thrombolytic agents exist. In the case of hypotension, recovery of proper pressure levels can hinder the progression of myocardial lesions.

Unstable angina - The same guidelines and warnings in relation to the use of nitrates and other medications commonly used in the treatment of this condition apply.

\section{Treatment of the hypotension resulting from the interaction of sildenafil with nitrates}

The following measures should be employed in sequence: 1) place the patient in the Trendelenburg's position; 2) administer intravenous fluids rapidly; 3) use intravenous alpha-adrenergic agonists, such as phenylephrine, ethylephrine, or metaraminol; 4) if necessary, use an alpha or beta agonist, such as norepinephrine to support blood pressure, but one should be aware of the risk of worsening or inducing myocardial ischemia; 5) install auxiliary support through the intra-aortic balloon.

\section{Limitations of the recommendations}

The recommendations here expressed result from a still limited experience in regard to some of the multiple clinical situations of patients with cardiovascular disease, who intend to use sildenafil. Therefore, the risk in face of these not yet tested situations is presumed based on what is known in regard to the pharmacokinetics and pharmacodynamics of the medication. This can be applied to situations such as heart failure, the first 6 months after an acute myocardial infarction or after a stroke, and uncontrolled hypertension, which are situations absent in the published studies. In addition, some other pending questions should be remembered due to their importance and to a better comprehensiveness of this study: a) interaction with platelet antiaggregating agents other than aspirin; b) interaction with other phosphodiesterase inhibitors, including specific (milrinone, vesnarinone, enoximone) and nonspecific (theophylline, dipyridamole, papaverine, and pentoxifylline) inhibitors; c) effects of sildenafil on the central nervous system (PDE5 is present in the brain); d) the isolated hypotensive effect of sildenafil in high-risk patients with heart disease (severe heart failure); e) effect on skeletal muscles (thoracic muscle pains that may be mistaken for angina); f) simultaneous use of alcoholic beverages, especially with antihypertensive agents.

\section{Final considerations}

Sildenafil has proved to be an effective and welltolerated medication; these characteristics may be extended to patients with ischemic heart disease. Therefore, the number of patients with cardiovascular disease willing to try the drug has been increasing. These patients, however, have two potential risks in relation to the use of sildenafil. The first is an indirect risk and relates to the ability to accomplish coitus, which is an activity associated with an increase in energy consumption and with varied degrees of psychological stress. The second is the risk of developing severe hypotension, which is directly linked to sildenafilnitrate interaction. In such circumstances, it is up to the cardiologist to decide and guide the patient in regard to the safe use of sildenafil.

This study, based on the existing scientific data, on recommendations of a working group of the American College of Cardiology and of the American Heart Association, and on our initial experience, aims to provide to physicians in general and more specifically to cardiologists the necessary information so that sildenafil can be used as safely as possible in patients with cardiovascular disease.

\section{References}

1. Sociedade Brasileira de Urologia - I Consenso Brasileiro de Disfunção Erétil. São Paulo: BG Cultural Ed.,1998: 1-3.

2. Greenstein A, Chen J, Miller H, et al. Does severity of ischemic coronary diseasecorrelate with erectile dysfunction? Int J Impot Res 1997; 9: 123-6.

3. Muller JE, Mittelman MA, Maclure M, Sherwood JB, Tofler GH. Triggering miocardial infarction by sexual activity - low absolute risck and prevention by regular physical exertion. JAMA 1996; 275: 1045-9.

4. Debusk RF. Sexual activity triggering miocardial infarction - one less thing to worry about. JAMA 1996; 275: 1447-8.
5. Goldstein I, Lue TF, Padma-natan H, et al. Oral sidenafil in the treatment of erectile dysfuncion. N Eng J Med 1998; 338: 1397-404.

6. Morales A, Gingell C Collins M, Wicker PA, Osterloh IH. Clinical safety of oral citrate (VIAGRA) in the treatment of erectile dysfunction. Int J Import Res 1998; 10: 69-74.

7. Feldman HA, Goldstein I, Hatzichristou DG, Krane RJ, McKinlay JB. Impotence and its medical and psychosocial correlates: results of the Massachusets male aging study. J Urol 1994; 151: 54-61.

8. Boolell M, Allen MJ, Ballard AS, et al. Sildenafil: na orally active type 5 cyclic 
GMP-specific phosphodiesterase inhibtor for the treatment of erctile penile dysfunction. Int J Impot Res 1996; 8: 47-52.

9. Rajfer J, Aronson WJ, Bush PA, Dorey FJ, Ignarro LJ. Nitric oxid as a mediator of relaxation of the corpus cavernosum in response to nondrenergic, noncholinergic neurotransmission. N Eng J Med 1992; 326: 90-4.

10. Turko IV, Francis SH, Corbin JD. Potencial roles of conserved amino acids in the catalic domain of the cGMP-binding cGMP-specific phosphodiesterase (PDE5). J Biol Chem 1998; 273: 6460-6.

11. ACC/AHA Expert Consensus Document. Use of sildenafil (Viagra) in patients with cardiovascular disease. J Am Coll Cardiol 1999; 33: 273-82.

12. Zusman RM. Cardiovascular data on sildenafil citrate. Am J Cardiol 1999; 83: $1 \mathrm{C}-35 \mathrm{C}$. 